\title{
Desenvolvimento de competência moral na formação médica
}

\author{
Development of moral competence in undergraduate medical education
}

Eliane Dias Gontijo' (D) | egontijo@medicina.ufmg.br

\begin{abstract}
RESUMO
Introdução: A prática da medicina requer competência moral, além de competências técnicas. Na formação médica, os docentes são corresponsáveis por apresentar os valores intrínsecos aos direitos humanos e mediar o desenvolvimento de atitudes, motivação e práticas, além de servirem como modelos aos jovens aprendizes.

Desenvolvimento: Educar em valores não significa que os professores podem escolher aqueles a serem seguidos pelos alunos. A competência moral compreendida como a capacidade de julgar e tomar decisões segundo princípios internos é uma habilidade, mais do que uma simples atitude, que pode e deve ser construída ao longo da vida. Assim, a educação/formação moral deve ser entendida como um processo que conduz o sujeito à reflexão sobre situações cotidianas, envolvendo dilemas morais. O futuro profissional tem a oportunidade de se sensibilizar para considerar a singularidade de cada situação diante de decisões e avaliações, bem como se responsabilizar pelas escolhas feitas e pelas suas consequências. Para o desenvolvimento da competência moral nos processos formativos, os professores devem ampliar, para além da transmissão de informações, a reflexão sobre o compromisso social e ético e buscar a formação de cidadãos autônomos, críticos e participativos. Acreditar que apenas o exemplo do professor é capaz de promover o desenvolvimento moral restringe a questão aos seus aspectos afetivos, pois, assim, não se vislumbram os aspectos cognitivos da formação moral e o pensamento crítico para o favorecimento da abordagem e condução de conflitos morais ao longo da vida acadêmica e profissional.
\end{abstract}

Conclusão: Os valores morais necessitam deixar de serem impostos por agentes externos e converterem-se em diretrizes internas, legitimadas pela própria pessoa e, portanto, desenvolvidas por meio de uma reflexão crítica, responsável, autônoma e criativa de cada sujeito. Mais do que aprender teorias ou discutir os grandes filósofos, os alunos devem ser capazes de despertar em si mesmos sentimentos e atitudes que os levem a valorizar convicções humanistas e humanitárias, e adotar comportamentos justos e empáticos como elementos essenciais da boa prática médica, de modo que se tornem moralmente competentes.

Palavras-chave: Educação Médica; Empatia; Habilidades Sociais; Moral; Desenvolvimento Moral.

\begin{abstract}
Introduction: The practice of medicine requires moral competence, in addition to technical competence. In medical training, professors are jointly responsible for presenting values intrinsic to human rights and for mediating the development of attitudes, motivation, and practices, as well as serving as a model for young apprentices.

Development: Educating on values does not mean that teachers can choose the values be followed by students. Moral competence understood as the ability to judge and make decisions according to internal principles is a skill, more than a simple attitude, which can and should be built throughout life. Thus, moral education/training must be understood as a process that leads the subject to reflect on everyday situations, involving moral dilemmas. The future professional has the opportunity to become aware of the uniqueness of each situation in the face of decisions and evaluations, as well as being responsible for the choices made and their consequences. For the development of moral competence in training processes, in addition to transmitting information, teachers must expand reflection on social and ethical commitment and seek the formation of autonomous, critical, and participatory citizens. Believing that only the teacher's example can promote moral development restricts the issue to its affective aspects, ignoring the cognitive aspects of moral education, and thereby favoring the approach and handling of moral conflicts throughout academic and professional life.
\end{abstract}

Conclusion: Moral values should no longer be imposed by external agents, but rather become internal guidelines, legitimized by the person, developed through a critical, responsible, autonomous, and creative reflection of each subject. More than learning theories or discussing great philosophers, students should be touched to spark feelings and attitudes that lead them to value humanistic and humanitarian convictions and to adopt fair, empathetic behavior as essential elements of good medical practice, thus becoming morally competent.

Keywords: Medical Education; Empathy; Social Skills; Ethics; Moral Development.

1 Universidade Federal de Minas Gerais, Belo Horizonte, Minas Gerais, Brasil.

Editora-chefe: Rosiane Viana Zuza Diniz.

Editor associado: Gustavo Antonio Raimondi.

Recebido em 08/06/21; Aceito em 24/10/21.

Avaliado pelo processo de double blind review. 


\section{INTRODUÇÃO}

Os médicos enfrentam cotidianamente situações que envolvem dilemas morais/conflitos éticos: decisões complexas em pacientes terminais, ocupação da única vaga em unidade de terapia intensiva e conduta médica versus autonomia do paciente. Ou ainda manipulação genética, tecnologias de reprodução assistida, iniquidades sociais, violação de direitos de vulneráveis..

$\mathrm{Na}$ tentativa de responder a tais desafios, foram sendo instituídos, ao longo da história, códigos, regulamentos e ordenamentos relativos à responsabilidade moral dos médicos no atendimento de pacientes. Contudo, à medida que as intervenções tecnológicas são incorporadas à prática médica, crescem, em frequência e complexidade, os problemas éticos decorrentes de seu uso. A relação médico-paciente foi se tornando mais impessoal, o que comprometeu os pressupostos morais clássicos: beneficência, não maleficência, confidencialidade e respeito. Assim, a distância que separa os médicos de seus pacientes transforma-se em lacuna ética, responsável pelos principais problemas éticos, e a insatisfação com a medicina e suas práticas se expressa em linguagem moral ${ }^{1}$. As pessoas apontam falhas e se queixam de descaso, direitos ignorados e não coincidência entre expectativas, deveres e obrigações dos envolvidos.

A prática da medicina requer virtude e caráter, além de competências técnicas. Assim, torna-se essencial discutir moralidade e aprofundar a reflexão sobre os dilemas criados pela biociência contemporânea. As instituições formadoras devem pensar estratégias educacionais efetivas para a abordagem de tema tão complexo, que possibilitem, para além de argumentos sustentados pela lei, pela filosofia e pela teologia, o desenvolvimento da competência moral em seus estudantes.

\section{MEDICINA É CIÊNCIA E ARTE}

A hegemonia da expertise técnica com poucas e deficientes pinceladas humanísticas começa na graduação, inspirada no avanço tecnológico e na negligência de dois outros domínios da formação de médica de qualidade: a competência humanística e a competência moral'.

No Brasil, o eixo ordenador da formação médica são as Diretrizes Curriculares Nacionais (DCN) para o curso médico, na versão atualizada em 2014, que reforçam a formação humanista e a atuação pautada em princípios éticos, com responsabilidade social $^{3}$. No plano internacional, o Comitê de Ética da Ciência e Tecnologia (World Commission on the Ethics of Scientific Knowledge and Technology - Comest) da Organização das Nações Unidas para a Educação, a Ciência e a Cultura (United Nations Educational, Scientific and Cultural Organization - Unesco) já recomendava, em 2003, o desenvolvimento nos estudantes de habilidades de reconhecer e analisar questões de ordem ética e ser capazes de chegar a decisões sobre como agir eticamente ${ }^{4}$. O documento, revisto em 2008, definiu como objetivos: desenvolver o interesse em questões éticas, compreender criticamente buscando alternativas e desenvolver a capacidade de análise ética e argumentação ${ }^{5}$.

A literatura aponta o descompasso entre o idealismo inicial dos estudantes de Medicina e o progressivo sentimento de quase cinismo e falta de comprometimento com os pacientes, que são reduzidos a números ou "casos interessantes" a serem discutidos e abordados ${ }^{6-8}$. Exposição ao sofrimento, sensação de impotência no cuidar e alteração das expectativas durante o processo de formação resultam em redução da empatia e contribuem para a desumanização da assistência9 .

Em um plano mais geral, o ensino superior tem sido confrontado com diversos desafios impostos pela sociedade contemporânea, que atravessa uma profunda crise de valores ${ }^{1}$. Nesse sentido, apesar da expectativa social em relaçãoà idoneidade ética do médico, observa-se que o tema é negligenciado durante os anos da formação universitária do estudante de Medicina e mesmo em programas de pós-graduação ${ }^{10}$.

Na formação médica, os docentes são corresponsáveis por apresentar os valores intrínsecos aos direitos humanos e mediar o desenvolvimento de atitudes, motivação e práticas, além de servirem como modelos no desempenho de suas atribuições profissionais. Entretanto, é importante entender e assumir que educar em valores, por exemplo, NÃO significa que os professores devem escolher os valores a serem seguidos pelos alunos. Essa postura pode levar a uma fala moralista ou moralizante. Numa sociedade plural, os valores não precisam ser os mesmos, mas precisam passar por um processo de crítica e escolha pessoal, antes de serem assumidos ou introjetados e postos em prática no momento de decisão².

Assim, a educação/formação moral pode ser entendida como um processo que conduz o sujeito à reflexão sobre situações cotidianas, nas quais estejam envolvidos valores morais. E esse processo de reflexão deve ser adotado nas tomadas de decisão ${ }^{10}$.

Muitas instituições planejam atividades curriculares na tentativa de introduzir princípios éticos, em longas e monótonas exposições, muitas vezes desvinculadas das vivências cotidianas, ou limitam-se a apresentar a deontologia determinada pela orientação prescritiva e restrita a um conjunto de normas e códigos trabalhados de forma teórica e abstrata11.

\section{DIFERENCIANDO ÉTICA DE MORAL}

Inicialmente, é importante estabelecer os marcos dentro dos quais serão utilizados os termos moral e ética, que, por serem conceitos polissêmicos, podem dificultar a comunicação. 
Neste ensaio, são utilizadas as concepções de Cortina ${ }^{12}$ que considera a ética um saber filosófico, uma reflexão sobre a moral $e$, dessa forma, uma avaliação resultante de uma análise crítica, enquanto a moral é externa ao indivíduo, pois sistematiza um conjunto de princípios, normas, preceitos e valores existentes em determinadas sociedades. A ética engloba a moral: somos éticos porque primeiramente somos seres morais ${ }^{12}$. Essa diferenciação é importante porque o ensino em ética utiliza estratégia pedagógica diferente daquela mais adequada ao desenvolvimento moral dos estudantes.

No cotidiano do trabalho em saúde, os estudantes vivenciam problemas morais que podem se tornar dilemas quando os valores morais se confrontam. La Taille ${ }^{13}$ considera que os termos ética e moral, apesar de inseridos em dimensões bem diferenciadas, são complementares. $\mathrm{O}$ autor defende que a instituição formadora deve ajudar os estudantes a resolver os conflitos e dilemas coletivamente, com base no respeito a princípios discutidos pela comunidade ${ }^{13}$. A moral, como um conjunto de normas de condutas em determinadas sociedades, vem de "fora" do indivíduo. A ética é um saber filosófico, uma reflexão sobre a moral, a compreensão dos critérios e valores que orientam o julgamento de uma conduta. Essas diferenças são importantes para as orientações pedagógicas, pois um ensino em ética tem diferenças conceituais e estratégicas de uma formação para o desenvolvimento moral, embora caminhem juntas. O ensino deve propiciar a reflexão das doutrinas éticas e morais para a tomada de decisão em contextos permeados por conflitos e dilemas ${ }^{14}$.

A prática médica demanda dos profissionais o conhecimento e a incorporação de valores intrínsecos à condição humana, para que possam atuar de acordo com esses valores e normas. A formação em bioética é importante, entretanto conhecer normas e princípios não é suficiente. $A$ formação deve buscar, além da aquisição de conhecimentos, o desenvolvimento de habilidades e valores atitudinais em benefício da qualidade do cuidado destinado ao paciente ${ }^{15}$.

O desenvolvimento do raciocínio moral pressupõe transformações das estruturas cognitivas, em estágios sequenciais, que são universais, ou seja, todos os sujeitos, independentemente da cultura, passarão pela mesma sequência, na mesma ordem. Entretanto, isso não significa que todos os sujeitos atingirão os estágios mais elevados. Para Bataglia et al. $^{16}$, a moralidade não pode ser entendida como simples questão de atitudes, mas está relacionada à aquisição de competência e cognição.

Kohlberg (1992) considera competência do juízo moral a capacidade de tomar decisões e julgar moralmente, isto é, baseado em princípios internos. O autor atribuiu grande importância à cognição e às competências morais, transformando a moralidade em assunto a ser pesquisado e que transcende o discurso religioso ou político. Para o desenvolvimento da competência moral, propõe atividades que desafiem o aluno e provoquem um conflito cognitivo e a discussão de dilemas morais, promovendo, desse modo, a educação moral sem doutrinação nem relativismo, ${ }^{17}$.

As pesquisas de Kohlberg deram sequência aos estudos de Piaget, por meio de um método clínico no qual os participantes precisavam explicar suas respostas a dilemas morais a serem resolvidos, em situações de conflito já instaurado. As proposições se tornaram bastante conhecidas, como o "dilema de Heinz", no qual um homem precisava conseguir um remédio para sua esposa com câncer. Os dilemas eram contados e perguntas eram feitas aos participantes de modo a obter respostas de diferentes indivíduos, em contextos diversos. Nesse sentido, a justificativa é mais importante do que a própria resposta ${ }^{16,17}$.

No julgamento moral, o conteúdo está representado pela cognição, e as justificativas, pelos valores. De modo similar à cognição, o desenvolvimento moral ocorre por meio da evolução de estágios, que são os mesmos para todos os indivíduos e seguem uma mesma ordem, de sucessivas estruturas que permitirão a passagem para os estágios mais avançados.

Kohlberg avançou na teoria piagetiana ao identificar o nível pós-convencional de raciocínio moral, contemplada no conceito de autonomia de Piaget ${ }^{16,17}$. O autor identificou seis estágios sequenciais e invariantes de julgamento moral, desde uma postura inicial de obediência incondicional à autoridade (estágio 1 do nível pré-convencional) até chegar ao ponto de basear as ações em princípios éticos universais internamente legitimados (estágio6 donível pós-convencional). Noestágio préconvencional, as expectativas sociais são externas ao indivíduo, enquanto no nível convencional a pessoa se identifica com as regras e expectativas sociais, especialmente de autoridades e de pessoas de referência. Já no nível pós-convencional, o indivíduo diferencia sua pessoa das normas e expectativas dos outros e define seus valores segundo princípios universais.

A teoria proposta por Lind 6 utiliza os pressupostos de Kohlberg e contempla dois aspectos da moralidade: o cognitivo e o afetivo ${ }^{17}$. Assim, Lind ${ }^{6}$ estabelece sua definição sobre o comportamento moral na tomada de decisão. Competência para Lind ${ }^{6}$ é mais do que uma simples atitude que pode e deve ser construída ao longo da vida. O Teste de Julgamento Moral considera o aspecto dual em que o afetivo e o cognitivo integram a compreensão do comportamento moral ${ }^{6}$. O autor foca a investigação da competência moral com base no pressuposto de que todos os sujeitos têm princípios morais, mas, para sua aplicação, as capacidades morais devem ter sido incentivadas pelos pais, pela escola ou pelas demais instituições formadoras ${ }^{17}$. 
Desse modo, os cursos de formação profissional devem desenvolver a capacidade reflexiva dos estudantes, a partir da possibilidade da discussão de situações concretas. O futuro profissional deve ter a oportunidade de se sensibilizar para considerar a singularidade de cada situação diante de decisões e avaliações, bem como se responsabilizar pelas escolhas feitas e por suas consequências. Nessa relação de formação, o educador deve desenvolver o questionamento e a interrogação reflexivos, críticos e constantes sobre suas decisões, inclusive sobre seus desdobramentos.

\section{LACUNAS NA FORMAÇÃO MORAL DE ESTUDANTES DE MEDICINA}

Posto que a formação médica pressupõe o desenvolvimento de competências morais que demandam a reflexão crítica, mais do que transferência de conceitos, torna-se relevante identificar se e como os futuros médicos estão sendo formados. Rego ${ }^{18}$, em 2003, já alertava que a graduação médica não estava preparando os estudantes para o enfrentamento dos desafios éticos da sociedade contemporânea.

Em 2010, o Exame Nacional de Desempenho dos Estudantes (Enade) foi aplicado em 28.938 estudantes de Medicina, sendo 11.407 (39\%) concluintes. A questão 2 do componente de formação geral pedia a interpretação de uma charge para avaliar a compreensão do conceito de ética. Houve $36 \%$ de acertos ${ }^{19}$. A análise global do desempenho desse componente mostrou mediana igual e média similar entre ingressantes e concluintes, podendo refletir a reduzida influência do curso no tema. Em 2016, o Enade foi aplicado apenas em concluintes, e a questão 4 que discutia o plágio na vida acadêmica apresentou somente $40 \%$ de acertos ${ }^{20}$.

Scheffer et al. ${ }^{21}$, ao entrevistarem 3.685 médicos recémformados no momento da inscrição nos 27 conselhos regionais, verificaram que $86 \%$ haviam vivenciado alguma conduta ética que julgaram inadequada ou assistido no curso a algum procedimento com a mesma característica. Os médicos recémformados assinalaram, em especial, a predominância (58\%) de situações relacionadas às relações com pacientes.

A diminuição da empatia e de outros valores morais ao longo do curso pode estar relacionada à dificuldade de identificar as questões éticas ou até a frequência de assédio moral sofrido pelos estudantes (principalmente nos estágios clínicos), analisá-las e atuar perante elas ${ }^{22,23}$. O conflito entre a confidencialidade e a beneficência, que ocorre na discussão de um "caso"com os pares para definir a melhor conduta, pode trazer certo desconforto moral, assim como tarefas e procedimentos delegados inapropriadamente podem ser modelos inadequados para o desenvolvimento moral do estudante ${ }^{23}$. $O$ assédio moral que pode abalar psicologicamente a dignidade e a integridade da pessoa ocorre, em geral, em ambientes em que predominam relações hierárquicas autoritárias e assimétricas, frequentes nos cenários de estágios e durante a residência médica ${ }^{24}$. Nesse sentido, um estudo com abordagem qualitativa identificou situações controversas: "discurso da relevância da ética médica se contrapõe à prática docente divergente, promovendo uma desarmonia com suas condutas e decisões" 25 .

Entrevistas realizadas com 128 estudantes de Medicina de uma universidade pública revelaram falhas no processo de formar médicos moral e tecnicamente competentes, reforçando a importância de o conteúdo ser discutido em todo o currículo, sobretudo durante as vivências clínicas ${ }^{26}$. Como o comportamento moral é construído na interação entre pessoas e influenciado pelo contexto sociocultural, devem ser utilizadas estratégias educacionais ativas, em pequenos grupos, não se limitando à exposição teórica ${ }^{27}$. Secchi et al. ${ }^{28}$, ao descreverem a experiência educacional de discussões semanais, em pequenos grupos, sobre assuntos morais e éticos relacionados à profissão médica, desde 2004, ressaltam o depoimento de egressos do curso sobre os benefícios dessa reflexão nas tomadas de decisão e nos posicionamentos inevitáveis no exercício da profissão ${ }^{28}$.

De acordo com Marques et al. ${ }^{29}$, apesar de os estudantes compreenderem a importância dos valores morais na formação médica, eles identificam reduzidas oportunidades de aprendizagem ao longo do curso. Os valores considerados mais relevantes na formação médica foram respeito, responsabilidade, paciência e humildade. Os autores observaram que as disciplinas que mais contribuíram para a discussão desses valores foram atividades com vivências práticas e discussões em pequenos grupos, em detrimento da oferta obrigatória de uma disciplina de ética, com reduzida contribuição (40\%) para a formação na percepção dos entrevistados ${ }^{29}$. Metodologia ativa e estratégias diversificadas para a discussão de ética contribuem para evitar a diminuição de valores morais com o avançar dos períodos de graduação ${ }^{30}$.

A ação de cuidar, inserida na esfera profissional, deve englobar tanto aspectos técnicos como atitudes, uma vez que empatia, compaixão, afeto e escuta também têm papel terapêutico ${ }^{31}$. A competência moral deve ser considerada estruturante no planejamento pedagógico da formação médica. Para tanto, deve-se exigir capacitação docente adequada ${ }^{29}$ para que a formação moral não fique restrita a um conteúdo periférico e não essencial às matrizes curriculares ou, ainda pior, gere inconsistência entre o discurso da relevância da ética e a prática docente divergente ${ }^{25}$. Nos processos formativos, os professores devem ampliar, para além da transmissão de informações, a reflexão sobre o compromisso social e ético, de modo a buscar o desenvolvimento moral de seus alunos e a formação de cidadãos autônomos, críticos e participativos. 


\section{CONSIDERAÇÕES FINAIS}

A formação médica ampliada de sujeitos crítico-reflexivos pressupõe desenvolver competências técnicas, emocionais e morais comprometidas com uma prática segura e qualificada.

Tradicionalmente, os conteúdos sobre humanismo, moral e ética nas escolas médicas estão relacionados aos aspectos da responsabilidade profissional, à confidencialidade e privacidade, à relação com o paciente, à morte e ao final de vida, e ao exercício lícito e ilícito da profissão. Sem dúvida, são questões importantes, mas, em geral, abordadas em uma perspectiva ou um direcionamento para a deontologia e em menor escala para a bioética, e, como estratégia educacional, utilizam-se seminários e conferências para grandes grupos.

Entretanto, se se deseja que o profissional seja capaz de lidar adequadamente com dilemas, deve-se ir além da transmissão de conteúdo teórico. Dificilmente o aluno ou profissional encontrará nos códigos de ética médica uma resposta pronta, única e definitiva até mesmo para questões cotidianas que emergem da prática clínica.

Acreditar que apenas o exemplo do professor é capaz de promover o desenvolvimento moral restringe a questão aos seus aspectos afetivos, pois, assim, não se vislumbram os aspectos cognitivos da formação moral para a promoção da competência moral, ou seja, da capacidade de julgamento moral, de modo a facilitar a abordagem e condução de conflitos morais ao longo da vida acadêmica e profissional.

É imprescindível que os valores morais não sejam mais impostos por agentes externos nem se convertam em diretrizes internas. Tais diretrizes devem ser legitimadas pela própria pessoa e desenvolvidas por meio de uma reflexão crítica, responsável, autônoma e criativa de cada sujeito.

Mais do que aprender teorias ou discutir os grandes filósofos, osalunos devemsercapazes dedespertaremsimesmos sentimentos e atitudes que os levem a valorizar convicções humanistas e humanitárias, e adotar comportamentos justos e empáticos como elementos essenciais da boa prática médica, de modo que se tornem moralmente competentes.

\section{CONFLITO DE INTERESSES}

Declaro não haver conflito de interesses.

\section{FINANCIAMENTO}

Declaro não haver financiamento.

\section{REFERÊNCIAS}

1. Drane J, Pessini L. Bioética, medicina e tecnologia: desafios éticos na fronteira do conhecimento humano. São Paulo: Edições Loyiola; 2005.

2. Rios IC. Humanização: a essência das ações técnica e ética nas práticas de saúde. Rev Bras Educ Med. 2009;33(2):253-61. doi: 10.1590/S010055022009000200013.
3. Brasil. Resolução CNE/CES n 3/2014. Diário Oficial da União, Brasília. Seçãol, p. 8-11.

4. United Nations Educational, Scientific and Cultural Organization. Report on the Working Group of the Teaching of Ethics of the World Commission on the Ethics of Scientific Knowledge and Technology (COMEST). Paris: Unesco; 2003.

5. United Nations Educational, Scientific and Cultural Organization. Bioethics Core Curriculum. Section 1: Syllabus ethics education programme. Unesco; 2008 [acesso em 05/06/2021 ]. Disponível em: http://unesdoc. unesco.org/images/0016/001636/163613e.pdf.

6. Lind G. O significado e medida da competência moral revisitada : um modelo do duplo aspecto da competência moral. Psicol Reflex Crit. 2000;13(3):399-416. doi: 10.1590/S0102-79722000000300009.

7. Moreto G, Blasco PG. A erosão da empatia nos estudantes de Medicina: um desafio educacional. RBM. Rev Bras Med. 2012;69:12-7.

8. Batley NJ, Nasreddine Z, Chami A, Zebian D, Bachir R, Abbas HA. Cynicism and other attitudes towards patients in an emergency department in a Middle Eastern tertiary care center. BMC Med Educ. 2016;16(36):1-9.

9. Dell Amore Filho $\mathrm{E}$, Dias RB, Toledo Jr AC. Ações para a retomada do ensino da humanização nas escolas de Medicina. Rev Bras Educ Med. 2018;42(4):14-28.

10. Varela MAB. Competência moral e formação médica: percepção dos docentes sobre a influência do ambiente universitário [dissertação]. Rio de Janeiro: Escola Nacional de Saúde Pública Sergio Arouca; 2013.

11. Rios IC. Humanidades médicas como campo de conhecimento em medicina. Rev Bras Educ Med. 2016;40(1):21-9.

12. Cortina A. O fazer ético: guia para a educação moral. São Paulo Moderna; 2003.

13. La Taille Y. Desenvolvimento humano: contribuições da psicologia moral Psicol USP. 2007;18(1):11-36. doi: 10.1590/S0103-65642007000100002.

14. Rennó HMS. Desenvolvimento de competências ético-morais e o sofrimento moral na formação em enfermagem. Belo Horizonte: Escola de Enfermagem da UFMG; 2015.

15. Carrese JA, Malek J, Watson K, Lehmann LS, Green MJ, McCullough $\mathrm{LB}$, et al. The essential role of medical ethics education in achieving professionalism: the Romanell Report. Acad Med. 2015;90(6):744-52.

16. Bataglia PUR, Morais A, Lepre RM. A teoria de Kohlberg sobre o desenvolvimento do raciocínio moral 2010. Estud Psicol (Natal). 2010;15(1):25-32.

17. Kohlberg L. (1992). Psicología del desarrollo moral. Bilbao, Desclée de Brouw-er. 1984.

18. Rego ST. A formação ética dos médicos: saindo da adolescência com a vida (dos outros) nas mãos. Rio de Janeiro: Fiocruz; 2003.

19. Instituto Nacional de Estudos e Pesquisas Educacionais Anísio Teixeira. Enade 2010: relatório síntese: Medicina. Brasília: Inep; 2010 [acesso em 05 jun 2021]. Disponível em: https://download.inep.gov.br/educacao_ superior/enade/relatorio_sintese/2010/2010_rel_sint_medicina.pdf.

20. Instituto Nacional de Estudos e Pesquisas Educacionais Anísio Teixeira Enade 2016: relatório síntese: Medicina. Brasília: Inep; 2016 [acesso em 05 jun 2021]. Disponível em: https://download.inep.gov.br/educacao superior/enade/relatorio_sintese/2016/medicina.pdf.

21. Scheffer M, Cassenote A, Guilloux AGA, Biancarelli A, Miotto BA, Mainard GM. Demografia médica no Brasil 2018. São Paulo: FMUSP, CFM; 2018 [acesso em 05 jun 2021]. Disponível em: https://jornal.usp.br/wp-content/ uploads/DemografiaMedica2018.pdf.

22. Hojat M, Vergare MJ, Maxwell K, Brainard G, Herrine SK, Isenberg GA, et al. The devil is in the third year: a longitudinal study of erosion of empathy in medical school. Acad Med. 2009;84(9):1182-91. doi: 10.1097/ ACM.0b013e3181b17e55.

23. Kong WM, Knight SJ. Bridging the education-action gap: a near-peer case-based undergraduate ethics teaching programme. Journal of Med Ethics. 2017;43(10):692-6. doi: 10.1136/medethics-2016-103762. 
24. Conselho Regional de Medicina do Estado de São Paulo. Assédio moral na formação médica: conscientizar para combater. São Paulo: Cremesp; 2019.

25. Garcia-Jr CAS, Verdi MIM. Dimensão dos problemas éticos implicados na educação médica. Rev Bras Educ Med. 2019;43(4):99-108.

26. Covenago Fillus I, Rodrigues $C$. Conhecimento sobre ética e bioética dos estudantes de medicina. Rev Bioét. 2019;27(3):482-9.

27. Shamim MS, Torda A, Baig LA, Zubairi N, Balasooriya C. Systematic development and refinement of a contextually relevant strategy for undergraduate medical ethics education: a qualitative study. BMC Med Educ. 2021;21:9. doi: 10.1186/s12909-020-02425-6.
28. Secchi L, Vieira BA. Quais são os valores morais essenciais para a formação médica? Rev Bras Educ Med. 2021;45(sup 1):e123. doi: https:// doi.org/10.1590/1981-5271v45.

29. Marques LMNSR, Fonseca SC, Milioni VC, Corbiceiro WCH. Quais são os valores morais essenciais para a formação médica? Rev Bioét. 2020;28(4):693-703. doi: 10.1590/1983-80422020284433.

30. Melo NW, Souza E, Barbosa L. Competência moral e espiritualidade na educação médica: realidade ou desafio? Rev Bras Educ Med. 2016;40(1):43-52.

31. Serodio A, Kopelman BI, Bataglia PUR. A promoção das competências moral e democrática: por uma virada educacional da bioética. Rev Bioét. (Impr.). 2016;24(2):235-42. doi: 10.1590/1983-80422016242123. 